\title{
Latinoamérica y Caribe, crisis, emergencias y solidaridad. Una mirada desde la Geopolítica del virus SARS-CoV-2
}

\author{
América Latina e Caribe, crise, emergências e solidariedade. Um olhar da \\ geopolítica do vírus SARS-CoV-2
}

\section{Latin America and the Caribbean, crisis, emergencies and solidarity. A look from the Geopolitics of the SARS-CoV-2 virus}

\author{
Juan Manuel Delgado Estrada \\ juan.delgado10@unmsm.edu.pe \\ https://orcid.org/0000-0002-2770-082X
}

Universidad Nacional Mayor de San Marcos/Universidad de Barcelona/UGI/CLACSO

\begin{abstract}
RESUMEN
El año 2020, será el año en que el mundo dejo de ser tal cual como se le conocía, pues se ocultaba muchas falencias y fallas del sistema - mundo, donde el meta relato de que estábamos en el camino correcto al modelo de desarrollo impuesto por las elites globales, se negó que existían problemas como el cambio climático, el hambre y se privilegió la economía por encima de la salud, educación y la seguridad de la población.

La colonialidad de Poder se ha evidenciado en las políticas públicas cortoplacistas y no desde una visión geopolítica con un horizonte desde la gobernanza y gobernabilidad de los territorios nacionales y subnacionales. El accionar de las elites latinoamericanas y caribeñas, imponiendo la economía cortoplacista frente a la salud durante la pandemia del virus SARS-CoV-2 no ha tenido ideologías ni quien fue el peor o mejor desde las derechas o las izquierdas, el lucro se impuso frente a la generosidad y el trabajo en común, pero también la ciudadanía se ha organizado desde abajo y en solidaridad y reciprocidad como bien lo hacían los pueblos originarios con el buen vivir o vivir bien.
\end{abstract}

Solo controlando la pandemia del virus SARS -Cov-2 se podrá iniciar la reactivación económica, no hay otra alternativa que poner la salud y la vida por encima de la economía y el lucro.

\begin{abstract}
This 2020 will be the year that the world ceased to be as it was known, since many flaws and failures of the world-system were hidden, where the meta story that we were on the right path to the development model imposed by the global elites. Problems such as climate change and hunger were denied, and the economy was prioritized over health, education, and security.

The arrival of the SARS -Cov-2 virus pandemic to our continent confirmed the fragility in providing essential services such as health from a state dismantled in the 80 's and 90 's by the directives of the
\end{abstract}

Delgado, J. (2020). Latinoamérica y Caribe, crisis, emergencias y solidaridad. Una mirada desde la Geopolítica del virus SARS-CoV-2. Espiral, revista de geografías y ciencias sociales, 2(4), 023 - 032. http://dx.doi.org/10.15381/espiral.v2i4.19530 
Washington consensus and the organizations multilateral financial institutions such as the IMF and the World Bank.

The coloniality of Power has been evidenced in short-term public policies and not from a geopolitical vision with a horizon from the governance and governability of national and sub-national territories. The actions of the Latin American and Caribbean elites imposing the short-term economy against health during the pandemic of the SARS-CoV-2 virus has not had ideologies nor who was the worst or best from the right or the left, profit was imposed against generosity and work in common, but also citizenship has been organized from below and in solidarity and reciprocity as the original peoples did well with good living or living well.

Only by controlling the SARS - Cov-2 virus pandemic can the economic reactivation be started, there is no alternative but to put health and life above economy and profit.

\section{RESUMO}

Este 2020 será o ano em que o mundo deixou de ser como era conhecido, uma vez que muitas falhas e falhas do sistema-mundo estavam escondidas, onde a meta-história de que estávamos no caminho certo para o modelo de desenvolvimento imposto pelas elites globais. Problemas como mudança climática e fome foram negados, e a economia teve prioridade sobre saúde, educação e segurança.

A chegada da pandemia do vírus SARS -Cov-2 ao nosso continente confirmou a fragilidade na prestação de serviços essenciais como a saúde de um estado desmantelado nas décadas de 80 e 90 pelas diretrizes do consenso de Washington e das organizações instituições financeiras multilaterais como o FMI e o Banco Mundial.

A colonialidade do Poder tem se evidenciado em políticas públicas de curto prazo e não a partir de uma visão geopolítica com um horizonte a partir da governança e governabilidade dos territórios nacionais e subnacionais. A ação das elites latino-americanas e caribenhas impondo a economia de curto prazo contra a saúde durante a pandemia do vírus SARS-CoV-2 não teve ideologias nem quem foi o pior ou o melhor da direita ou da esquerda, impôs-se lucro contra generosidade e trabalho em comum, mas também cidadania se organizou de baixo para cima e na solidariedade e reciprocidade, pois os povos indígenas viviam bem ou viviam bem.

Somente controlando a pandemia do vírus SARS -Cov-2 pode a reativação econômica ser iniciada, não há alternativa a não ser colocar a saúde e a vida acima da economia e do lucro.

PALABRAS CLAVES: SARS -Cov-2; geopolítica; salud; Covid-19; pandemia; Latinoamerica.

KEYWORDS: SARS -Cov-2; geopolitics; Health; Covid-19; pandemic; Latin America.

PALAVRAS-CHAVE: SARS -Cov-2; geopolítica; Saúde; Covid-19; pandemia; América latina.

\section{La coyuntura de la pandemia del virus SARS-CoV-2}

La estructura del poder global está en crisis, la pandemia del virus SARS- CoV2 ha evidenciado muchos problemas estructurales del patrón de desarrollo de la modernidad /colonialidad, que tantas veces, prometía que tal fase de la historia era ese horizonte que necesitaba nuestro continente para ingresar al ciclo económico de bienestar.

Pareciera que no hemos aprendido de la última crisis global del 2008 y en este momento estamos ingresando a una geografía del desastre, siempre se pensó que los desastres son naturales, pues no es así, es un fenómeno social, porque es la mala decisión del hombre la que genera este desastre socio-natural, tal como lo explica la metodología FORIN (Forensic Investigations of Disasters) ${ }^{1}$.

Beck $^{2}$, nos dice que para tener conciencia del daño ambiental es necesario que se conozca el simbolismo que los relaciona, en el caso ambiental es tangible y real, en cambio en lo cultural es invisible y muy difícil combatirlo, y esto último es lo que sucede con elSARS-CoV-2, se tiene que conocer el riesgo pues como es abstracto genera

1 A. Oliver-Smith, I. Alcántara-Ayala, I. Burton and A. M. Lavell (2016).

2 Beck, Ulrich (2002). 
miedo y pánico, y es lo que está sucediendo en este momento cuando uno (01) de cada Cuatro (04) personas en el mundo está en cuarentena por este desequilibrio que se ha dado en esa relación metabólica social con la naturaleza, y lo estamos padeciendo.

No tenemos certezas si la pandemia del coronavirus SARS-CoV-2 ó COVID - 19, es un accidente de la naturaleza o una creación humana, y no es interés de este documento por lo menos no es urgente. La urgencia es como este virus ha sacado lo mejor de la humanidad, pero también lo peor, nos ha mostrado o mejor dicho ha evidenciado que algunas decisiones de nuestras élites nos han llevado a un Colapso ${ }^{3}$ de la relación social con la naturaleza, y negando que los problemas ambientales globales como el cambio climático, contaminación ambiental y el calentamiento global.

Este 2020 todos los especialistas de diversas disciplinas académicas coinciden que el SARS-CoV-2 coronavirus más conocido como COVID -19 nos dejara una línea temporal en lo económico, lo cultural y la vida misma, una pandemia desconocida e invisible que nos da miedo y nos a confinado a la cuarentena $(20+20)$, como lo señala David Harvey ${ }^{4}$.

La diplomacia internacional no son solamente relaciones políticas a escala gubernamental, sino también tiene algo de subjetividades o "diplomacia personal"5 como me lo dijo el profesor Wagner Tadeu Iglecias en noviembre del 2018 en Buenos Aires - Argentina durante la Conferencia CLACSO 2018.

El 03 de marzo la International Association of Health Policy tuvo una reunión virtual como nos comentó Vicenç Navarro 6 , los expertos de muchas disciplinas concordaron que ya lo habían informado y pronosticado en el 2018, que la epidemia SARS - CoV (síndrome respiratorio agudo grave), eran parte de esas alertas que fueron ignoradas por los políticos y empresarios, es decir por los países centrales y por las transnacionales, se continuó con los recortes presupuestales de sectores estratégicos entre ellos salud, se continuaron con reformas económicas priorizando el pago de deudas de la crisis financiera del 2008 de parte de los países europeos ${ }^{7}$. En Latinoamérica con el ascenso de gobiernos de derechas, se inició un nuevo ciclo económico, se dejó de priorizar la educación, por ende, ciencia y tecnología e innovación que generalmente los gobiernos progresistas habían invertido proyectos y programas aprovechando los altos precios de los commodities para la redistribución de la renta de los recursos naturales, aunque lo ideal era darle valor agregado con trasferencia tecnológica y modificar la matriz productiva primaria exportadora.

En Latinoamérica y el Caribe, muchos países décadas atrás abandonaron la salud como política de estado, precarizaron sus servicios, y en algunos países como el Perú que registró un gasto público per cápita por debajo del promedio de América Latina (Banco Mundial, 2016), se permitieron la tercerización y el ascenso del servicio médico privado sin control estatal, con un afán de lucro desmedido. Los gobiernos progresistas a inicios del siglo XXI iniciaron reformas con relativo éxito pues las elites profesionales de médicos frente a otros profesionales de salud perdían privilegios y se oponían a estos cambios, en otros países se lograron algunos avances como el acceso universal a la salud pública, quizás insuficiente, pero era un inicio después de décadas de que la salud era un botín para empresas de ese sector, y de esta forma volver a ser un servicio público como un derecho humano garantizado en sus constituciones.

Retornando a la crisis geopolítica generada por el virus SARS-CoV-2, ya con los estudios que se mencionaron, pues se sabía que existían los recursos económicos

3 Diamond, Jared (2005).

4 Harvey, David (2020). Política anticapitalista en tiempos de COVID-19. Recuperado el 23 de marzo de 2020, http://www. sinpermiso.info/textos/politica-anticapitalista-en-tiempos-de-covid-19

5 Malamud, Andrés (2011).

6 Navarro, Vicenç. (2020). Lo que se está ocultando en el debate sobre la pandemia. Recuperado el 27 de marzo de 2020 , https://blogs.publico.es/vicenc-navarro/2020/03/24/lo-que-se-esta-ocultando-en-el-debate-sobre-la-pandemia/ 7 Weber, Christoph S. (2015). 
para realizar investigaciones sobre los virus y las epidemias que ha sucedido en las últimas décadas en varios países. En plena guerra fría la ex URSS y USA llegaron a compartir proyectos de lucha, quizás el más claro ejemplo fue la lucha contra la Polio, que con tiempo, dinero e intercambio de investigaciones de estos enemigos acérrimos pero que por el bien de la humanidad se pudieron realizar experimentos, pruebas y colaboraciones entre equipos epidemiológicos de ambos países, pero aquí es donde otra vez llegamos a la diplomacia personal de los líderes mundiales, nos fijamos especialmente en Donald Trump quien al ser el líder de la principal potencia que en el pasado lideró las luchas de control sanitario global frente a brotes epidemiológicos en Asia y África, hoy frente a la pandemia no solo no lidero esta crisis global sino que no aplico medidas preventivas para salvaguardar a su población, y fue el ojo de la tormenta del contagio por varias semanas.

Así como se sabía que estaba latente una epidemia como el SARS - CoV (síndrome respiratorio agudo grave), el MERS - $\mathrm{CoV}^{8}$ (síndrome respiratorio de Oriente Medio) y también el EVE (Ébola) ${ }^{9}$, nos los hicieron saber el primero (SARS) desde el $2003^{10}$, pero no se quiso o no se logró consensuar como hacerlo. Solo en el 2016 luego del brote en el África Occidental los políticos y tecnócratas de los países centrales y hegemónicos además de los organismos multilaterales financieros le prestaron atención, pero no con la debida fuerza para al menos financiar las investigaciones y tratamientos que los académicos venían adelantando y sus advertencias sobre estas amenazas a la especie humana para los próximos años.

Es la primera vez que dos crisis globales del mundo se confluyen, la histórica, la societal o de la geografía humana, la otra ambiental, climática, ó de la geografía física, así nos decía Aníbal Quijano ${ }^{11}$, está en crisis el modelo de desarrollo económico capitalista y su impacto en el medioambiente. En medio de este problema sanitario - ambiental que se volvió crisis global aparece este virus, que luego de ser una epidemia en China ha pasado a ser una pandemia global.

La Unión Europea fácticamente en este momento no existe, cada país se ha refugiado dentro de sus fronteras, luego del gran rescate del 2008 al sistema bancario europeo con el aval alemán y la generación del eurobono, la propuesta de contener a la crisis económica de los países confinados a la cuarentena como España e Italia ha tenido resistencia de los gobiernos de los Países Bajos y Alemania, que sugieren que solo se invoque al MEDE - Mecanismo de Ayuda Europeo, creado para la crisis del euro y no hay solución o consenso a la vista, y si lo hubiera quedan los antecedentes de las condiciones duras de la Troika Europea ${ }^{12}$ de la crisis financiera del 2008/2009. No podemos dejar de mencionar que a finales del 2020 se deberá de tener claro el Brexit que es la salida del Reino Unido después de 47 de la Union Europea.

La Organización Mundial de la Salud - OMS, a solo 3 meses de conocer el SARSCoV-2, emite un protocolo médico que se va construyendo día a día, la burocracia mundial como los organismos adscritos al sistema de la ONU y los multilaterales no han tenido un desempeño ético pues se han contradicho varias indicaciones de prevención, pero sobretodo de priorizar la economía global (OMS, 29 febrero 2020), se entiende con la presión de las Multinacionales. La Geoeconomía Mundial se impuso

\footnotetext{
8 Apareció en el 2012 en Arabia Saudita en el 2012, es un coronavirus que se encuentra en murciélagos pero que tuvo a los camellos como medio de transmisión del patógeno a los humanos.

9 El Ébola apareció en 1976 en Nzara en los que hoy es Sudán del Sur y Yambuku en lo que hoy es el Congo y antes Zaire, el brote se ubicó muy cerca del rio Ébola donde el virus tomo el nombre. La epidemia de Ébola que se dio el África occidental entre el 2014 - 2016 que se inició en Guinea, luego Sierra Leona y Liberia. Esta epidemia fue el primer aviso de que estábamos vulnerables a una enfermedad zoonotica y que no deberíamos descuidarnos.

10 Infobae. (2020) Escapar de la caja de Pandora: el desafío mundial frente al COVID - 19. Recuperado el 04 de abril del 2020, https://www.infobae.com/america/ciencia-america/2020/04/04/escapar-de-la-caja-de-pandora-el-desafiomundial-frente-al-covid-19/

11 Conferencia de Inauguración del XIV Encuentro de Geógrafos de América Latina 8 de abril en Lima 2013 de Aníbal Quijano "Geografia de la Resistencia”.

12 La Troika Europea son la Comisión Europea (CE), el Banco Central Europeo (BCE) y el Fondo Monetario Internacional (FMI), estos organismos tomas decisiones sobre la política económica financiera de la zona Euro.
} 
y no se permitió cerrar aeropuertos y el traslado del vector fue impresionantemente rápido para que las agencias o o ministerios de salud pudieran dictar protocolos de bioseguridad a una pandemia desconocida.

Latinoamérica y el Caribe siendo la región más desigual del mundo, no está preparada para una pandemia de estas características, y los gobiernos viven el día a día y no pueden ejercer una geopolítica, con políticas cortoplacistas y reactivas, la geopolítica de la pandemia es solo para los países ricos.

La mayoría de la economía en Latinoamérica y el Caribe es informal, en algunos países llega a ser casi $3 / 4$ como es el caso de Perú con el $72.8 \%$ del total de la fuerza laboral del país (INEI, 2014), los estratos sociales bajos sobreviven con ingresos precarios y de subsistencia (OIT, 2014), la población más vulnerable no puede estar en cuarentena por mucho tiempo y los gobiernos lo saben, pero no sabemos que políticas de contención y ralentización del contagio se aplicaran mientras continuamos conociendo al virus.

La colonialidad del poder a través del Consenso de Washington que ejerce EE.UU. en Latinoamérica y Caribe ha contribuido a que nuestros países, con su sistema de salud públicos débiles y no preparados para enfrentar la pandemia, sean mucho más vulnerables y que ante su nula respuesta de apoyo de EE.UU. hayan sido por primera vez China, Rusia y Cuba los países de donde ha provenido la ayuda con personal médico y equipos para el tratamiento y diagnóstico del virus, es aquí en donde la geopolítica de pandemia de visibiliza también en Europa que reciben apoyo de material médico cuando era el ojo de la tormenta global de contagio del virus.

¿Que hacer, frente a esta emergencia?, que se convirtió en crisis y estamos a un paso de pasar al estado de catástrofe, aunque los gobiernos no lo desean aceptar y se puede comprender que se desconoce a este nuevo virus, muchos sistemas de salud colapsaron y visibilizaron que la salud es un derecho humano y no debería ser un privilegio o una forma de lucrar como ha sucedido desde décadas atrás.

La vulnerabilidad social es evidente en Latinoamérica y el Caribe, la desigualdad social se acentuará y su impacto será en salud a los adultos mayores en su mayoría, en jóvenes desempleados o subempleados, migrantes enganchados en labores eventuales todos desprotegidos frente a la crisis económica que ya está en un escenario de recesión mundial. Las cifras según la CEPAL son muy duras con la pérdida de 8.5 millones de puestos de trabajo en un mercado laboral que, previo a la crisis de la COVID-19, contaba con un $40 \%$ de los trabajadores sin acceso a ninguna clase de protección social y donde el 60\% labora de manera informal (Informe Perspectivas económicas de América Latina 2020).

Latinoamérica y el Caribe tenían una previsión de crecimiento para el 2020 de 1,3\%, en medio de la crisis de la pandemia COVID - 19 el estimado de la caída del PBI es mínimo $1,8 \%$ pero pudiera ser entre $3 \%$ y $4 \%$ o más, dependiendo de las medidas que se tomen para contrarrestar la recesión sea nacional, regional o mundial (CEPAL, 2020).

No se tiene la vacuna en este momento y pasarán meses en tener certezas de su existencia, pero eso no impide luchar contra la pandemia del virus SARS-CoV-2 por eso países como China, Corea del Sur, Taiwán, Alemania y Singapur han utilizado las recomendaciones médicas con una lógica de geolocalización, visualización en tiempo real del problema epidémico, predicción de transmisión con base en modelos para monitorear al vector epidémico, asignar espacialmente el riesgo y evaluar la vulnerabilidad, selección del control de daños. Además, se ha podido gestionar geoespacialmente el material médico, desde asignar lugares de toma de test rápidos, hasta generar control del pánico y terror de los focos infecciosos a través del GeoApp de cada país. 
Los países desarrollados y las grandes empresas transnacionales utilizan los Sistema de Información Geográfica - SIG para la planificación del uso del territorio, actividades económicas y control de impactos ambientales entre otros usos de la investigación militar/científica/tecnológica ${ }^{13}$ que, sumado a nuevas tecnologías como bigdata geoespacial, inteligencia artificial, Internet de las cosas (IoT) y la tecnología de nube, complementan una lucha frontal contra el SARS-CoV-2. Esto permite primordialmente la ingesta de información masiva a través de la Neogeografia ${ }^{14}$ o mapas ciudadanos que generan Bigdata geoespacial, monitoreo en tiempo real del problema epidémico, modelo del patrón de transmisión en base al vector epidémico, asignar espacialmente el riesgo y evaluar la vulnerabilidad, selección del control de daños ${ }^{15}$.

Pero no todo se resuelve con el software sino el acceso a los geodatos, su integración y su proceso con el análisis respectivo, y solo lo realizan los gobiernos, empresas y universidades o como se dice innovación de triple hélice ${ }^{16}$, aunque en este modelo tiene más énfasis al inicio para la industria militar, luego con la participación de la sociedad civil se enfoca que es la búsqueda del desarrollo óptimo y sostenible a través de las políticas públicas y ese el momento que la innovación de cuádruple hélice.

El más claro ejemplo del trabajo en común de la industria de la geotecnologia lo da ESRI ${ }^{17}$ quienes ponen sus geotecnologias como ArcGIS Online y ArcGIS Hub para apoyar a las instituciones públicas o académicas de salud como la Universidad de Johns Hopkins quienes monitorean el SARS-CoV-2 a escala global en tiempo real. Para lograr contener al vector infeccioso del SARS-CoV-2 con una lógica de geolocalización se ha necesitado vulnerar la privacidad de las personas, acceder a sus datos personales, lo cual induce a una gran controversia porque da mucho temor de que los gobiernos logren tener acceso información de sus ciudadanos pudiendo ser considerada invasiva a la privacidad de la ciudadanía en nombre de la salud pública ${ }^{18}$.

Para que esto que sucede en Latinoamérica y el Caribe, con el acceso y la ingesta a esa geoinformación primordialmente se deberá cerrar la brecha digital que en la actualidad excluye a 280 millones de personas que no utilizan Internet (CAF, 2019), teniendo en consideración que el 2017 más del 80\% de la población estaba conectada a Internet móvil en Chile, Brasil, Costa Rica y el Uruguay, esa cifra se reducía al 30\% en Guatemala, Honduras, Haití y Nicaragua (CEPAL, 2020) ${ }^{19}$. Si se quisiera utilizar la geotecnologia para contener al vector de contagio del SARS-CoV-2 sería muy limitado en muchos países por la conectividad y calidad del acceso al servicio del internet, hoy Latinoamérica y el Caribe padecen la poca inversión en infraestructura en Tecnologías de la Información y la Comunicación - TICs, casos extremos son las desigualdades extremas de conectividad entre los quintiles más ricos y los más pobres que es mayor en Perú con 60 puntos porcentuales y Honduras con 58 puntos porcentuales (CEPAL, 2020). Hoy Latinoamérica y el Caribe sufren no ser productoras de Geotics más bien ser solo usuarios lo cual confirma que somos altamente vulnerables.

13 Delgado Estrada, Juan Manuel (2014).

14 Capel, Horacio (2012).

15 Chenghu Zhou, Fenzhen Su, Tao Pei, An Zhang, Yunyan Du, Bin Luo, Zhidong Cao, Juanle Wang, Wen Yuan, Yunqiang Zhu, Ci Song, Jie Chen, Jun Xu, Fujia Li, Ting Ma, Lili Jiang, Fengqin Yan, Jiawei Yi, Yunfeng Hu, Yilan Liao, Han Xiao. (2020). 16 Etzkowitz, Henry (2008).

17 ESRI significa Environmental Systems Research Institute, fue fundada en 1969 por Jack Dangermond. ESRI apoya al gobierno Chino a través del Centro Chino para el Control y Prevención de Enfermedades (CDC) y trabajaron juntos un panel de control y prevención de enfermedades https://mp.weixin.qq.com/s/i-22baCPvuAfiNeQpsyUQQ

18 Pero se dan casos contrarios como en el Perú donde el gobierno peruano a pesar de tener apoyo del pequeño ecosistema de innovación, ciencia y tecnología no ha logrado un trabajo articulado para generar soluciones tecnológicas ni siquiera con el apremio de la emergencia sanitaria, o que las geotecnologias son de libre acceso, bajo costo, pero sobretodo una herramienta para la gestión pública implementado en otros países como seguimiento de contactos digital.

19 A pesar que la gran brecha digital de America Latina y el Caribe a quedado evidenciado frente a la crisis generada por las cuarentenas muy restrictivas para controlar a la pandemia de COVID -19 que la conexión a internet en 40 millones de hogares aprox. no existe conectividad por lo que no pueden participar en las actividades remotas que los gobiernos sugieren a entidades públicas y privadas en teletrabajo y teleducación (CEPAL, 2020). 


\section{Recomendaciones}

Finalmente, nuestras recomendaciones frente a esta geopolítica del desastre de la Pandemia SARS-CoV-2, es que no se debe de repetir los errores de la crisis financiera del 2008, pues esta crisis es sanitaria que se ha transformado en una recesión económica mundial que todavía no se tiene clara las dimensiones, es de pronóstico reservado, pero eso no implica que los gobiernos deben de priorizar la economía sobre la salud. El Estado tiene en este momento un papel importante en la lucha sanitaria y económica para que el impacto en los sistemas de salud y económico no sean tan nefastos para los países que han aplicado la cuarentena como una medida de control de daños a la infección del virus SARS-CoV-2.

Luego de contener y bajar la métrica al vector de contagio, positividad y el uso de camas de unidades de cuidados intensivos (UCI), doblando (aplanando) la curva, solo así los gobiernos nacionales tendrían que aplicar una política fiscal y monetaria expansiva reactivando la economía de los países latinoamericanos y caribeños bajo un modelo macroeconómico keynesiano ${ }^{20}$, controlar la pandemia es controlar la economía. El desafío es el diseño de una política de que el ahorro de los agentes económicos como las familias y empresas por la incertidumbre de la crisis global de la pandemia no han invertido o consumido. El instrumento económico seria el aumento del gasto público en diversas obras de infraestructura como: servicios básicos, conectividad de internet y fortalecimiento del sistema de salud. El siguiente paso urgente seria coordinar con los bancos centrales de cada país para bajar la tasa referencial de interés. Pero todo esto debería estar acompañado de una política social de cerrar las brechas que el modelo económico neoliberal se impuso en diversos países de Latinoamerica y el Caribe, todo esto como un nuevo pacto social entre los actores sociales, solo así los países latinoamericanos y caribeños tendría una visión de largo plazo y estar mejor preparados para una nueva crisis sistémica metabólica como la del 2008, hoy 2020 y la que próxima que estamos seguro no será muy lejana.

Por último, es necesario activar la Cooperación Internacional científica - tecnológica - económica que en momentos tan tensos de la guerra fría del siglo XX se pudieron realizar en bien de la especie humana, pero hoy estas relaciones multilaterales están afectadas por la lucha geopolítica entre el unilateralismo norteamericano y el multilateralismo que su momento fueron los BRICS que hoy China y Rusia han tomado el mando de este bloque geoestratégico luego de la caída de Brasil alineándose a EE.UU. y que la India y Sudáfrica han mantenido un perfil bajo.

La geopolítica nos prepara para un cambio de Era luego de la geografía del desastre, el mundo luego del mañana que se logre controlar la pandemia del virus SARS-CoV-2 es probable que sea diferente, el detalle que no se tiene claro es que si el patrón de desarrollo moderno colonial será modificado o se reinventará como lo hizo en el 2008 en donde las desigualdades se profundizaron entre países y las sociedades de estas, es el momento de que el "buen vivir, vivir bien ó sumac kausay" con su solidaridad y reciprocidad sea ya una alternativa a esa globalización hegemónica de los capitales financieros.

La pandemia ha evidenciado que muchos estados latinoamericanos y caribeños no cuentan con sistemas de información territorial, con acceso libre a los geodatos, o peor aún que no se comparten entre las diversas instituciones nacionales o subnacionales. En el caso del Perú aparte de todo eso, no se produce editorialmente un Atlas desde 1989, teóricamente un atlas sintetiza mapas temáticos que recogen esa geoinformación,

20 “El economista británico John Maynard Keynes encabezó una revolución del pensamiento económico que descalificó la idea entonces vigente de que el libre mercado automáticamente generaría pleno empleo, es decir, que toda persona que buscara trabajo lo obtendría en tanto y en cuanto los trabajadores flexibilizaran sus demandas salariales (recuadro). El principal postulado de la teoría de Keynes es que la demanda agregada -la sumatoria del gasto de los hogares, las empresas y el gobierno- es el motor más importante de una economía. Keynes sostenía asimismo que el libre mercado carece de mecanismos de auto-equilibrio que lleven al pleno empleo. Los economistas keynesianos justifican la intervención del Estado mediante políticas públicas orientadas a lograr el pleno empleo y la estabilidad de precios" (Sarwat, J., Mahmud, A. S., \& Papageorgiou, C: 2014). 
siendo esta una herramienta útil para los tomadores de las decisiones (políticos) pues tiene un fin de prospectiva en la gestión del territorio nacional y subnacional, además es compendio educativo de la construcción imaginada del estado - nación para las jóvenes. En el mundo contemporáneo, todo país organizado bajo la forma de un Estado democrático, institucionalizado y eficiente, publica por lo menos una vez cada década, un Atlas oficial.

Recordemos el mito griego de Pandora y su caja de regalo de bodas que no debió abrir, Pandora no hizo caso y la abrió, desde la caja salieron los males de la humanidad, luego de cerrarla se percató que solo estaba elpis que representaba la esperanza, el único bien frente a los males encerrados en la caja. Abrimos la caja, es momento de cerrarla y la esperanza es lo último que se pierde, pero quizás es el impulso que necesitamos como especie para cambiar el sistema - mundo ${ }^{21}$.

\section{Notas}

1. Durante la parte final de este texto gracias a su autor Rogério Haesbert desafortunadamente tuve conocimiento de su último trabajo en la JLAG sobre "Território(s) numa perspectiva latino-americana", el cual es muy esclarecedor de lo que estamos viviendo en este momento sobre la pandemia en Latinoamerica y el Caribe y su dinámica social en el territorio, pero ahora enfocándola desde el virus SARS-CoV-2, que podría generar tres categorías como práctica, normativa y de análisis.

2. Ya Haesbaert nos había propuesto un concepto de "multiterritorialidad" (1997, 2001a, 2002a, 2004a), donde se desarrollan múltiples territorios con sus procesos complejos de: territorialización, desterritorialización y reterritorialización. Siguiendo ese patrón de la re/de/construcción social del territorio y territorialidad, ejerciendo un dominio o miedo para ejercer ese poder, es exactamente lo que hace el virus SARS-CoV-2 con los espacios públicos ejerciendo un territorialidad con territorio, porque este tiene historicidad y el vector epidémico somos nosotros, pues este terror (miedo) ha reconfigurado y no se sabe su impacto multiescalar de la dominación política - administrativa - económica de un continente, país y ciudad, obligando a quien ejerce ese poder a reconfigurarse y ser flexible a quien en este momento ejercer mayor terreo territor (terror, aterrorizar) y domina el territorio.

3. Nuestro mayor temor es que las élites políticas económicas direccionen a sus gobiernos nacionales y establezcan "zonas o territorios de sacrificio" de la pandemia del virus SARS-CoV-2, tal cual existen en muchos países, el profesor Hugo Romero (2018) nos mencionó los ejemplos de bahías de Quintero-Puchuncaví y Coronel en la región Valparaíso en Chile. En Perú un territorio conocido y reconocido por el gobierno peruano es Cerro de Pasco con más de 30 actas de compromiso a dar solución que han incumplido, donde 12 metales pesados han sido detectados en la sangre de niños y que la contaminación ambiental ha pasado a segundo plano en nombre del desarrollo y la actividad minera.

4. Un país de renta media como el Perú tiene que ejercer una justicia espacial (Edward W. Soja, 2014) y lo que ha sucedido es todo lo contrario, un gobierno toma decisiones en base al conocimiento científico y de los saberes locales. El virus SARS-CoV-2 ha desnudado que las políticas públicas han sido excluyentes y los que deciden en los gobiernos pareciera que no usan los servicios públicos como salud, educación y transporte, entonces como planifican sin ser usuarios. Toda resolución de crisis y conflictos tiene que ser con una lógica de justicia espacial y no de territorios de sacrificio. 
5. El deseo de participar en esta convocatoria en medio de la primera pandemia del siglo XXI es abrir y provocar el debate dentro de las geografías y las ciencias sociales sobre este fenómeno social metabólico, desde su genesis, la propagación global y su impacto en la vida misma de la especie humana evidenciando que hoy más que nunca encontrándonos en el Antropoceno tenemos una relación de dependencia con la naturaleza y la vida.

Hemos sacrificado en cuerpo, ideas y territorios a la naturaleza humana y no humana en el mundo pero nos interesa conocer más de ello en Latinoamerica y el Caribe, con un patrón de desarrollo moderno/colonial que ha "oprimido" a los territorios de los pueblos originarios con esa extirpación de idolatrías (cosmovisión), sometimiento de sus cuerpos y manipulación de sus emociones, pero sobretodo ha intentado desconocer el saber primigenio de su convivencia con la naturaleza que los pueblos originarios llaman el buen vivir o vivir bien.

El virus SARS CoV -2 ha evidenciado con la pandemia que recorre Latinoamerica y el Caribe que el modelo de desarrollo impuesto por las elites latinoamericanas y caribeñas no dan más, que es modelo económico, político y social impuesto por el eurocentrismo en clave de la colonialidad del poder está en crisis sistémica el mundo de hoy.

\section{Referencias Bibliográficas}

Beck, Ulrich. (2002). La sociedad del riesgo global. Siglo XXI de España Editores. 292 páginas. ISBN: 84-323-1083-2.

Capel, Horacio. (2010). Geografía en red a comienzos del Tercer Milenio. Por una ciencia solidaria y en colaboración. Scripta Nova. Revista Electrónica de Geografía y Ciencias Sociales. Barcelona: Universidad de Barcelona, vol. XIV, $\mathrm{n}^{\circ}$ 313. Recuperado el 12 de agosto del 2018. <http://www.ub.es/geocrit/sn/sn-313.htm>. ISSN: 11389788 1138-9788.

Centro Nacional de Planeamiento Estratégico. (2016). Economía informal en Perú: situación actual y perspectivas. CEPLAN. 56 paginas. Recuperado 15 de diciembre 2019 https:// www.ceplan.gob.pe/documentos_/economia-informal-en-peru/

Comisión Económica para América Latina y el Caribe. (2020). América Latina y el Caribe ante la pandemia del COVID-19: efectos económicos y sociales. 3 abril 2020. CEPAL. Recuperado 06 de abril 2020. <https://www.cepal.org/es/publicaciones/45337-americalatina-caribe-la-pandemia-covid-19-efectos-economicos-sociales>.

Corporación Andina de Fomento. (2020). Cerrar la brecha digital en América Latina y el Caribe depende críticamente de la transformación de los Fondos de Servicio Universal. Recuperado el 10 de abril2020. <https://www.caf.com/es/actualidad/noticias/2019/07/ cerrar-la-brecha-digital-en-america-latina-y-el-caribe-depende-criticamente-de-latransformacion-de-los-fondos-de-servicio-universal/>.

Chenghu Zhou, Fenzhen Su, Tao Pei, An Zhang, Yunyan Du, Bin Luo, Zhidong Cao, Juanle Wang, Wen Yuan, Yunqiang Zhu, Ci Song, Jie Chen, Jun Xu, Fujia Li, Ting Ma, Lili Jiang, Fengqin Yan, Jiawei Yi, Yunfeng Hu, Yilan Liao, Han Xiao. (2020). COVID-19: Challenges to GIS with Big Data, Geography and Sustainability. Recuperado el 16 de marzo del 2020. <http://www.sciencedirect.com/science/article/pii/S2666683920300092>.

Delgado Estrada, J. (2014). Geotecnologías de la información en el Perú: historia, usos y aplicación en la educación peruana. Ar@cne. Revista electrónica de recursos en Internet sobre Geografía y Ciencias Sociales. Barcelona: Universidad de Barcelona, $\mathrm{n}^{\circ} 189$. Recuperado el 15 de abril del 2018. <http://www.ub.es/geocrit/aracne/aracne-189.htm>.

Delgado Estrada, J. (2014). "De la Geografía a las Geografías en el Perú: Hacia una Geografía de la des/Colonialidad del poder" en Revista YUYAYKUSUN. Universidad Ricardo Palma. Número 07, 082-090. ISSN 2073-6150. Diciembre 2014. <http://revistas.urp.edu.pe/index. php/Yuyaykusun/article/view/205/192>. [Abril de 2017]. 
Delgado Estrada, J. (2019). De la geopolítica de la dominación a las geografías políticas de la des/colonialidad del poder. Espiral, Revista De Geografías Y Ciencias Sociales, 1(1), 059074. https://doi.org/10.15381/espiral.v1i1.15846

Diamond, Jared. (2005). Colapso: por qué unas sociedades perduran y otras desaparecen. Editorial: debate. Madrid. 752 pp. ISBN: 8483066483.

Etzkowitz, Henry. (2008). The triple helix: university-industry-government innovation in action (en inglés). Routledge. 180 páginas. ISBN 9780415964517.

Haesbaert, Rogério. (2020). "Território(s) numa perspectiva latino-americana," Journal of Latin American Geography 19(1): 141-151. DOI: 10.1353/lag.2020.0007. Recuperado 28 de marzo 2020. <https://muse.jhu.edu/article/744032 >.

Haesbaert, Rogério. (2010). Território e multiterritorialidade: um debate. GEOgraphia. 9. 10.22409/GEOgraphia2007.917.a13531.

Hudson-Smith, Andrew \& Crooks, Andrew \& Gibin, Maurizio \& Milton, Richard \& Batty, Michael. (2009). NeoGeography and Web 2.0: Concepts, tools and applications. J. Location Based Services. 3. 118-145. 10.1080/17489720902950366. Recuperado 29 de mayo 2020. $<$ https://www.researchgate.net/publication/267777698_Neogeography_Tools_and_ Applications $>$.

Instituto Nacional de Estadística e Informática. (2014). Producción y empleo informal en el Perú. Cuenta Satélite de la Economía Informal 2007-2012. INEI.

Malamud, Andrés. (2011). La política externa de Dilma Rousseff: ¿menos de lo mismo? Iberoamericana. América Latina, España, Portugal: Ensayos sobre letras, historia y sociedad. Notas. Reseñas iberoamericanas. Vol. 11, Núm. 41. Recuperado el 01 de enero de 2020. <https://journals.iai.spk-berlin.de/index.php/iberoamericana/article/ view/1042/722>.

Oliver-Smith, I. Alcántara-Ayala, I. Burton and A. M. Lavell. (2016). Forensic Investigations of Disasters (FORIN): a conceptual framework and guide to research (IRDR FORIN Publication No.2). Beijing: Integrated Research on Disaster Risk. 56 pp.

Organización Mundial de la Salud. (2020). Recomendaciones actualizadas de la OMS para el tráfico internacional en relación con el brote de COVID-19. OMS. 29 de febrero de 2020. Recuperado 27 de marzo 2020. <https://www.who.int/ith/2019-nCoV_advice_for_ international_traffic-rev/es/>.

Organización Internacional del Trabajo. (2014). Panorama Laboral Temático: Transición a la formalidad en América Latina y el Caribe. Lima: OIT, Oficina Regional para América Latina y el Caribe, 2014. 80 p. Recuperado el 15 de marzo del 2020. <https://www.ilo.org/wcmsp5/ groups/public/---americas/---ro-lima/documents/publication/wcms_315054.pdf>.

Quijano, Aníbal. (2000). "Colonialidad del poder, eurocentrismo y América Latina», en Edgardo Lander (ed.) La Colonialidad del Saber: eurocentrismo y ciencias sociales. Perspectivas Latinoamericanas. Buenos Aires: CLACSO. Recuperado el 14 de junio del 2014. <http://bibliotecavirtual.clacso.org.ar/clacso/sur-sur/20100708034410/lander.pdf>.

Sarwat, J., Mahmud, A. S., \& Papageorgiou, C. (2014). ¿Qué es la economía keynesiana? , Finanzas y Desarrollo, Septiembre de 2014, 53-54

Sierra, Jaime. (2018). La cuarta hélice y la financiación de la innovación. Journal of Economics, Finance and Administrative Science, 23(45), 128-137. Recuperado el 19 de abril de 2020, de http://www.scielo.org.pe/scielo.php?script=sci_arttext\&pid=S2077$18862018000200002 \& \operatorname{lng}=\mathrm{es} \&$ tlng $=\mathrm{es}$

Weber, Christoph S.. (2015). La Euro Crisis: Causas y síntomas. Estudios fronterizos, 16(32), 150-172. Recuperado en 01 de abril de 2020, de <http://www.scielo.org.mx/scielo. php?script=sci_arttext\&pid=S0187-69612015000200009\&lng=es\&tlng=es $>$. 